\title{
Phenotypic and genotypic characterization of glycopeptide, aminoglycoside and macrolide resistance among clinical isolates of Enterococcus faecalis: a multicenter based study
}

\author{
Mehrdad Zalipour ${ }^{1}$, Bahram Nasr Esfahani ${ }^{2}$ and Seyed Asghar Havaei ${ }^{1,2^{*}}$
}

\begin{abstract}
Objectives: Enterococcus faecalis as part of the normal floras of human gastrointestinal and genitourinary tracts are an important cause of nosocomial infections. The present study aimed to investigate the prevalence of genes encoding antimicrobial resistance and genetic relatedness of clinical isolates of E. faecalis among Iranian hospitalized patients.

Results: Antibiotic susceptibility testing results indicated that 53 (22.8\%) out of 232 E. faecalis isolates were vancomycin resistant (MIC $\geq 256 \mu \mathrm{g} / \mathrm{ml}$ ). All of the 53 vancomycin-resistant $E$. faecalis isolates carried the vanA and ermB genes; whereas aac (6')-le aph (2'), msrA, and ermA gene were found in $96.2 \%, 30.2 \%$ and $3.8 \%$ of vancomycin-resistant isolates, respectively. ERIC-PCR typing revealed that 53 vancomycin-resistant isolates were classified into 14 ERIC types. In our results, the high level of resistance to gentamicin, erythromycin and vancomycin in enterococci isolates were mainly related to the presence of aac (6')-le aph (2'), ermB and vanA genes, respectively. Meanwhile, ERIC-PCR analysis demonstrated that most of the evaluated isolates have a close genetic relatedness.
\end{abstract}

Keywords: Enterococcus faecalis, Antibiotic resistance, vanA, ermB, aac (6')-le aph (2')

\section{Introduction}

Enterococci are Gram-positive microorganisms and common commensal bacterium of human and animals digestive system [1]. Enterococcus faecalis, particularly vancomycin-resistant strains are an important cause of nosocomial infections such as bacteremia, sepsis, endocarditis, urinary tract infection (UTI) and wound infection [1]. The combination of a cell wall active agent (ampicillin, penicillin, or vancomycin) and an aminoglycoside, typically gentamicin has been used frequently for treatment of serious enterococcal infections [2]. However, treatment of enterococcal infections could be

\footnotetext{
*Correspondence: havaei@med.mui.ac.ir

${ }^{1}$ Department of Microbiology, School of Medicine, Isfahan University

of Medical Sciences, Hezar Jarib St, Isfahan, Iran

Full list of author information is available at the end of the article
}

difficult due to increasing resistance of enterococci to antimicrobial agents such as b-lactams, high-level resistance to aminoglycosides and more recently to glycopeptides [3].

The emergence and limited therapeutic options of vancomycin-resistant enterococci (VRE) have become a substantial clinical and epidemiological concern since critical ill patients such as patients with end-stage renal disease are at higher risk of colonization and subsequently more complication and treatment cost [4-6]. There are nine types of vancomycin-resistant cluster genes ( $\operatorname{van} A$ to $v a n N$ ), that $v a n A$ and $\operatorname{vanB}$ possess the greatest clinical significance and are the most commonly reported types in VRE worldwide [7, 8]. High-level resistance to the aminoglycosides usually occurs by the bifunctional aminoglycoside-modifying enzymes (AMEs) 
with both 6 'aminoglycoside acetyltransferase and $2^{\prime \prime}$ aminoglycoside activities, encoded by the structural gene aac (6')-Ie aph (2") which reduce the effect of aminoglycosides, with the exception of streptomycin $[9,10]$. The more frequent macrolide resistance determinants in enterococci are ribosomal target modification by $23 \mathrm{~S}$ rRNA methylases encoded by the erythromycin resistant methylase (erm) genes [11, 12]. This modification of the ribosomal target causes crossed resistance to macrolide, lincosamide, streptogramin (MLS) group of antibiotics [12]. The second major macrolide resistance mechanism is active efflux which encoded by the msrA or mef $A$ genes [13].

Understanding the local molecular epidemiology of VRE is necessary to control the spread of this bacteria in hospital setting. For this purpose, several valuable genotyping methods including ribotyping, pulsed-field electrophoresis (PFGE) and Polymerase Chain Reactionbased techniques are available [14]. Moreover, among DNA-based typing tools, the enterobacterial repetitive intergenic consensus (ERIC)-PCR as a simple, sharp and reproducible typing methods are suitable for local typing of enterococci [15]. Given the importance of vancomycin-resistant Enterococci in hospital-acquired infection and there is limited data regarding the molecular properties of VRE isolates in our region, the aim of this study was to determine the frequency of genes encoding antimicrobial resistance and genetic relatedness of clinical isolates of $E$. faecalis among Iranian hospitalized patients.

\section{Main text \\ Methods}

In this cross-sectional study during April 2017 to October 2017, a total of 232 E. faecalis isolates were collected from specimens of patients hospitalized in four University Teaching Hospitals in Isfahan, central part of Iran. They were obtained from different clinical specimens including urine, wound, blood, tracheal and other body fluids. Identification of the enterococci was performed based on the standard microbiological tests including Gram staining, catalase reaction, growth on Brain Heart Infusion agar with $6.5 \% \mathrm{NaCl}$, and bile-esculin test. The ddlE gene was targeted using species-specific primers for confirmation of E. faecalis isolates as described previously [1].

All of E. faecalis isolates were screened for phenotypic susceptibility against 11 antimicrobial agents by disc diffusion method on the Mueller-Hinton Agar (Merck Co., Darmstadt, Germany) based on Clinical and Laboratory Standards Institute (CLSI) guideline [16]. The tested antibiotics (Mast Group Ltd., UK.) were vancomycin $(30 \mu \mathrm{g})$, teicoplanin $(30 \mu \mathrm{g})$, erythromycin $(15 \mu \mathrm{g})$, gentamicin $(120 \mu \mathrm{g})$, ampicillin $(10 \mu \mathrm{g})$, ciprofloxacin $(5 \mu \mathrm{g})$, tetracycline $(30 \mu \mathrm{g})$, nitrofurantoin $(300 \mu \mathrm{g})$, rifampin $(5 \mu \mathrm{g})$, fosfomycin $(200 \mu \mathrm{g})$ and linezolid $(5 \mu \mathrm{g})$. Measurement of minimal inhibitory concentration (MICs) of vancomycin was performed by the E-test strips (Liofilchem, Italy) on the Mueller-Hinton Agar accordance with CLSI guideline [16].

PCR was done for detection the vanA and $v a n B$ genes, responsible for resistance to vancomycin, aac (6')-Ie aph $\left(2^{\prime \prime}\right)$ gene encoding high level resistance to gentamicin and ermA, ermB, msrA and mefA genes for macrolide resistance among $E$. faecalis isolates with high level resistance to vancomycin $[10,17]$. To do PCR, first bacterial cells were lysed and DNA extraction was done according to the method described by Heidari et al. [15] and was then amplified in $25 \mu \mathrm{l}$ reaction mixtures containing $2 \mu \mathrm{l}$ of template DNA, $1 \mu \mathrm{l}$ of each primer for studied genes, $9 \mu \mathrm{l}$ of Master Mix, and $12 \mu \mathrm{l}$ of sterile distilled water. PCR was performed in an Bio-Rad thermocycler with an initial denaturation step of $5 \mathrm{~min}$ at $95^{\circ} \mathrm{C}$, followed by 30 cycles of $1 \mathrm{~min}$ at $94{ }^{\circ} \mathrm{C}, 1 \mathrm{~min}$ at $50-60{ }^{\circ} \mathrm{C}$ according the type of primer and $1 \mathrm{~min}$ at $72{ }^{\circ} \mathrm{C}$, and a final extension step of $5 \mathrm{~min}$ at $72{ }^{\circ} \mathrm{C}$. The PCR products were analyzed by electrophoresis in $1 \%$ agarose gels with $1 \times$ TAE (Tris/Acetate/EDTA) buffer and photographed under ultraviolet illumination after staining with safe stain load dye (CinnaGen Co., Iran).

All VRE isolates were selected for analysis by ERICPCR and primer sequence used in this study as described previously [18]. To do ERIC-PCR was used of the protocol described in Heidari et al. study [15]. Amplified products were assessed by electrophoresis through $1 \%$ agarose gels at $60 \mathrm{~V}$ for $3 \mathrm{~h}$ in a $0.5 \times \mathrm{TBE}$ (Tris/Borate/EDTA) buffer and DNA bands were visualized using ultraviolet light after staining with safe stain load dye (CinnaGen Co., Tehran, Iran). ERIC patterns were analyzed using GelJ software, as described previously [20]. Isolates with a similarity coefficient equal or above $90 \%$ were clustered as the same genotypes.

Differences in the frequency of resistance genes and antimicrobial resistance pattern between selected $E$. faecalis isolates were analysed using the Chi-square test for each antimicrobial agent. A difference was considered statistically significant if the P-value was less than 0.05 .

\section{Results}

During 6 months of the study, a total of 232 E. faecalis isolates were isolated from different clinical specimens. Overall, $70 \%$ of isolates were collected from urine samples and $30 \%$ from other clinical samples. About $45 \%$ of 
E. faecalis isolates were isolated from male and $55 \%$ from female patients.

Among 232 E. faecalis isolates, the highest antibiotic resistance was seen against tetracycline (93.5\%) followed by erythromycin $(87 \%)$, and ciprofloxacin $(80 \%)$. None of the isolates was found to be resistant to fosfomycin and linezolid. Antibiotic susceptibility testing results indicated that $53(22.8 \%)$ isolates were vancomycin resistant $(\mathrm{MIC} \geq 256 \mu \mathrm{g} / \mathrm{ml})$. More than half of the isolates (52.5\%) were high-level gentamicin resistance. In addition, the antibiotic resistance against vancomycin, teicoplanin, ampicillin and gentamicin were significantly higher among vancomycin-resistant $E$. faecalis than vancomycin-susceptible $E$. faecalis $(\mathrm{P}<0.001)$. Moreover, the full results of antibiotic resistance pattern and comparison of the susceptibility patterns of vancomycin-resistant $E$. faecalis and vancomycin-susceptible $E$. faecalis to antibiotics are presented in Table 1.

All of the 53 vancomycin-resistant E. faecalis isolates carried the $v a n A$ gene, whereas the $\operatorname{van} B$ gene was not seen in any of this isolates. Also, aac (6')-Ie aph (2') gene was found in $96.2 \%$ of vancomycin-resistant isolates. The results of the amplification of erythromycin encoding genes showed that all vancomycin-resistant isolates were positive for ermB, whereas erm $A$ and $m s r A$ genes were found $3.8 \%$ and $30.2 \%$, respectively. Meanwhile, mef A gene was not found in any of the vancomycin-resistant isolates. The coexistence of $\operatorname{erm} B$ and $\operatorname{erm} A$ among vancomycin-resistant isolates were $3.8 \%$. The resistance genes distribution and resistance patterns among vancomycin-resistant $E$. faecalis are shown in Table 2.

Dendogram and Gel electrophoresis image of ERICPCR products from E. faecalis strains was showed in Fig. 1. The number of bands was varied from 3 to 10 bands and the size ERIC fragments ranged from $100 \mathrm{bp}$ to $1.5 \mathrm{~kb}$. ERIC-PCR typing revealed that 53 vancomycin-resistant isolates were classified into 14 ERIC types according to $90 \%$ cut off. The predominant type was A which containing 27 isolates. Moreover, six isolates were clustered in genotype $\mathrm{B}$, followed by $\mathrm{C}$ type (four), D (three), E (two), F (two), G (two isolates) and other isolates were distributed in scattered patterns and showed 7 single types (Fig. 1). According to our results, 46 (86.8\%) isolates were classified into 7 main genotypes (A-G). However, our study results showed that most of the examined strains have a close genetic relatedness. The heterogeneity amongst the isolates obtained from UTIs was more than other infections (Table 2).

\section{Discussion}

In recent decade's enterococci, especially E. faecalis have been emerged as an important cause of healthcareassociated infections [1]. In the present study, more than $22 \%$ of isolated $E$. faecalis were vancomycin-resistant but the results of recent meta-analysis studies in Iran have revealed lower rates of VRE isolation from clinical specimens [20]. Moreover, increasing VRE prevalence among hospitalized patients was also reported previously from several studies in the country $[8,21]$. In this study, all VRE isolates carried $v a n A$ gene and none of them has vanB gene. Similarly, previous researches had indicated that the $v a n A$ gene is typically responsible for high-level resistance to glycopeptides in the E. faecalis isolates [7, 21-23]. In contrast to our results, Samadi et al. in Tabriz and Rengaraj et al. of India showed that the $v a n B$ genotype is the predominant type of vancomycin resistance in E. faecalis isolates $[8,24]$. Resistance to vancomycin in enterococci could lead to the appearance of multidrugresistant strains resulting in failure of antimicrobial therapy with increased morbidity and mortality in patients

Table 1 Antibiotic resistance pattern of Enterococcus faecalis isolates, no. (\%)

\begin{tabular}{|c|c|c|c|c|c|c|c|c|c|}
\hline \multirow[t]{2}{*}{ Antimicrobial agent } & \multicolumn{3}{|c|}{$\begin{array}{l}\text { No. }(\%) \text { of vancomycin-resistant } \\
\text { isolates } \\
(\mathrm{N}=53)(\%)\end{array}$} & \multicolumn{3}{|c|}{$\begin{array}{l}\text { No. (\%) of vancomycin-susceptible } \\
\text { isolates } \\
(\mathrm{N}=179)(\%)\end{array}$} & \multicolumn{3}{|c|}{$\begin{array}{l}\text { Total no. }(\%) \text { of isolates } \\
(\mathrm{N}=232)(\%)\end{array}$} \\
\hline & $\mathrm{S}$ & I & $\mathbf{R}$ & $\mathrm{S}$ & I & $\mathbf{R}$ & $\mathrm{S}$ & I & $\mathbf{R}$ \\
\hline Teicoplanin & $2(3.8)$ & $0(0)$ & $51(96.2)$ & $174(97.2)$ & $5(2.8)$ & $0(0)$ & $176(75.8)$ & $5(2.2)$ & $51(22.0)$ \\
\hline Ampicillin & $22(41.5)$ & - & $31(58.5)$ & $146(81.5)$ & - & $33(18.5)$ & $168(72.4)$ & - & $64(27.6)$ \\
\hline Tetracycline & $5(9.5)$ & $0(0)$ & $48(90.5)$ & $10(5.5)$ & $0(0)$ & 169 (94.5) & $15(6.5)$ & $0(0)$ & $217(93.5)$ \\
\hline Ciprofloxacin & $1(1.8)$ & $2(3.8)$ & $50(94.4)$ & $9(5.0)$ & 35 (19.5) & $135(75.5)$ & $10(4.0)$ & $37(16.0)$ & $185(80.0)$ \\
\hline Erythromycin & $0(0)$ & $0(0)$ & $53(100)$ & $5(2.7)$ & $25(14.0)$ & 149 (83.3) & $5(2.3)$ & $25(10.7)$ & $202(87.0)$ \\
\hline Nitrofurantoin & $43(81.2)$ & $0(0)$ & 10 (18.8) & $155(86.5)$ & $0(0)$ & $24(13.5)$ & $198(85.3)$ & $0(0)$ & $34(14.7)$ \\
\hline Rifampin & $16(30.2)$ & $13(24.5)$ & $24(45.3)$ & $69(38.5)$ & 39 (21.8) & $71(39.7)$ & 85 (36.6) & $52(22.4)$ & 95 (41.0) \\
\hline Gentamicin & 10 (18.9) & $0(0)$ & 43 (81.1) & $102(57.0)$ & $0(0)$ & 77 (43.0) & $110(47.5)$ & $0(0)$ & $122(52.5)$ \\
\hline Linezolid & $53(100)$ & $0(0)$ & $0(0)$ & 179 (100) & $0(0)$ & $0(0)$ & $232(100)$ & $0(0)$ & $0(0)$ \\
\hline Fosfomycin & $53(100)$ & $0(0)$ & $0(0)$ & 179 (100) & $0(0)$ & $0(0)$ & $232(100)$ & $0(0)$ & $0(0)$ \\
\hline
\end{tabular}


Table 2 The distribution of resistance genes and resistance patterns among vancomycin-resistant Enterococcus faecalis isolates

\begin{tabular}{|c|c|c|c|c|c|c|}
\hline No. of isolates & $\begin{array}{l}\text { Male (M) } \\
\text { Female (F) }\end{array}$ & Source & Ward & Resistance patterns & Resistance genes & ERIC types \\
\hline 1 & M & Urine & Infectious diseases & AMP, TEC, VAN, CIP, E, TET, GEN & VanA, ermB, aac (6')-le aph (2') & G \\
\hline 3 & M & Urine & ICU & TEC, VAN, CIP, E, TET, GEN & VanA, ermB, aac (6 $\left.6^{\prime}\right)$-le aph (2') & $A$ \\
\hline 5 & M & Catheter & ICU & TEC, VAN, CIP, E, TET, GEN & VanA, ermB, aac (6')-le aph (2') & $A$ \\
\hline 6 & $\mathrm{~F}$ & Urine & Emergency & TEC, VAN, CIP, E, TET, GEN & VanA, ermB, aac (6')-le aph (2') & $E$ \\
\hline 8 & $\mathrm{~F}$ & Urine & Outpatient & AMP, TEC, VAN, E, TET, GEN & VanA, ermB, aac (6')-le aph (2') & $A$ \\
\hline 10 & $\mathrm{~F}$ & Wound & Surgery & RIF, TEC, VAN, CIP, E, TET, GEN & VanA, ermB, aac (6')-le aph (2') & $A$ \\
\hline 15 & M & Blood & Infectious diseases & AMP, RIF, TEC, VAN, CIP, E, TET, GEN & VanA, ermB, msrA, aac (6')-le aph (2') & $A$ \\
\hline 16 & M & Urine & Emergency & AMP, TEC, VAN, CIP, E, TET, GEN & VanA, ermB, msrA, aac (6')-le aph (2') & $A$ \\
\hline 18 & M & Urine & Internal & TEC, VAN, CIP, E, TET, GEN & VanA, ermB, aac (6')-le aph (2') & $A$ \\
\hline 25 & $\mathrm{~F}$ & Urine & Emergency & TEC, VAN, E, TET & VanA, ermA, ermB & Single \\
\hline 29 & $\mathrm{~F}$ & Blood & Respiratory & AMP, RIF, TEC, VAN, CIP, E, TET, GEN & VanA, ermB, aac (6')-le aph (2') & $C$ \\
\hline 30 & $\mathrm{~F}$ & Urine & Internal & AMP, RIF, TEC, VAN, CIP, E, TET, GEN, FM & VanA, ermB, aac (6')-le aph (2') & $D$ \\
\hline 31 & $\mathrm{~F}$ & Urine & Internal & AMP, TEC, VAN, CIP, E, TET, GEN, FM & VanA, ermB, aac (6')-le aph (2') & $C$ \\
\hline 32 & M & Urine & Internal & AMP, RIF, VAN, CIP, E, TET, GEN & VanA, ermB, msrA, aac (6')-le aph (2') & $A$ \\
\hline 35 & $\mathrm{~F}$ & Urine & ICU & AMP, TEC, VAN, CIP, E, TET, FM & VanA, ermB, msrA, aac (6')-le aph (2') & $A$ \\
\hline 40 & $\mathrm{~F}$ & Urine & Emergency & TEC, VAN, CIP, E, TET, GEN & VanA, ermB, aac (6')-le aph (2') & Single \\
\hline 41 & $\mathrm{~F}$ & Urine & Surgery & AMP, RIF, TEC, VAN, CIP, E, TET, GEN & VanA, ermB, aac (6')-le aph (2') & $A$ \\
\hline 44 & $\mathrm{~F}$ & Urine & Rheumatology & TEC, VAN, CIP, E, TET & VanA, ermB, aac (6')-le aph (2') & $A$ \\
\hline 51 & M & Urine & ICU & AMP, TEC, VAN, CIP, E, TET, GEN & VanA, ermB, msrA, aac (6')-le aph (2" & $A$ \\
\hline 52 & M & Urine & Surgery & TEC, VAN, CIP, E, TET GEN & VanA, ermB, aac (6')-le aph (2" & $A$ \\
\hline 54 & $\mathrm{~F}$ & Tracheal & ICU & AMP, TEC, VAN, CIP, E, TET, GEN & VanA, ermB, msrA, aac (6')-le aph (2') & $A$ \\
\hline 66 & $\mathrm{~F}$ & Wound & Rheumatology & TEC, VAN, E, TET & VanA, ermB, aac (6')-le aph (2') & Single \\
\hline 67 & $\mathrm{~F}$ & Urine & Urology & AMP, RIF, TEC, VAN, CIP, E, TET, GEN & VanA, ermB, aac (6 $\left.6^{\prime}\right)$-le aph (2') & Single \\
\hline 70 & M & Wound & Internal & AMP, TEC, VAN CIP, ETET & VanA, ermB, aac (6')-le aph (2') & $D$ \\
\hline 72 & M & Urine & ICU & AMP, RIF, VAN, CIP, E, TET, GEN & VanA, ermB, aac (6')-le aph (2') & $F$ \\
\hline 78 & $\mathrm{~F}$ & Urine & NICU & AMP, RIF, TEC, VAN, CIP, E, TET, GEN & VanA, ermB, aac (6')-le aph (2') & G \\
\hline 79 & M & Wound & Infectious diseases & AMP, RIF, TEC, VAN, CIP, E, TET, GEN & VanA, ermA, ermB, aac (6')-le aph (2') & $A$ \\
\hline 87 & $\mathrm{~F}$ & Eye & NICU & TEC, VAN, CIP, E, TET & VanA, ermB, aac (6')-le aph (2') & $F$ \\
\hline 90 & M & Tracheal & ICU & TEC, VAN, CIP, E, TET, GEN & VanA, ermB, aac (6')-le aph (2') & $A$ \\
\hline 92 & $\mathrm{~F}$ & Urine & Internal & AMP, RIF, TEC, VAN, CIP, E & VanA, ermB, aac (6')-le aph (2') & $B$ \\
\hline 101 & $\mathrm{~F}$ & Tracheal & ICU & RIF, TEC, VAN, CIP, E, TET, GEN & VanA, ermB, aac (6')-le aph (2') & Single \\
\hline 102 & $\mathrm{~F}$ & Urine & Respiratory & AMP, RIF, TEC, VAN, CIP, E, GEN, FM & VanA, ermB, aac (6')-le aph (2') & $B$ \\
\hline 103 & $\mathrm{~F}$ & Urine & ICU & TEC, VAN, CIP, E, TET, GEN & VanA, ermB, aac (6')-le aph (2') & $A$ \\
\hline 113 & M & Chest & Surgery & AMP, RIF, TEC, VAN, CIP, E, GEN & VanA, ermB, msrA, aac (6')-le aph (2') & $B$ \\
\hline 115 & M & Urine & $\mathrm{ICU}$ & AMP, RIF, TEC, VAN, CIP, E, TET, GEN, FM & VanA, ermB, aac (6')-le aph (2') & $B$ \\
\hline 117 & M & Urine & Internal & AMP, RIF, TEC, VAN, CIP, E, TET, GEN, FM & VanA, ermB, msrA, aac (6')-le aph (2') & $B$ \\
\hline 118 & M & Abscess & Internal & AMP, TEC, VAN, CIP, E, TET, GEN & VanA, ermB, msrA, aac (6')-le aph (2') & $A$ \\
\hline 122 & M & Abscess & ICU & AMP, RIF, TEC, VAN, CIP, E, TET, GEN, FM & VanA, ermB, aac (6')-le aph (2') & $A$ \\
\hline 144 & $\mathrm{~F}$ & Tracheal & Internal & RIF, TEC, VAN, CIP, E, TET, GEN & VanA, ermB, msrA, aac (6')-le aph (2') & $A$ \\
\hline 145 & $\mathrm{~F}$ & Urine & ICU & AMP, TEC, VAN, CIP, E & VanA, ermB, msrA, & $B$ \\
\hline 146 & M & Urine & Emergency & AMP, RIF, TEC, VAN, CIP, E, TET, GEN, FM & VanA, ermB, msrA, aac (6')-le aph (2') & $D$ \\
\hline 156 & $\mathrm{~F}$ & Urine & Internal & AMP, TEC, VAN, CIP, E, TET, GEN, FM & VanA, ermB, aac (6')-le aph (2') & $A$ \\
\hline 160 & $\mathrm{~F}$ & Urine & ICU & AMP, RIF, TEC, VAN, CIP, E, TET, GEN & VanA, ermB, msrA, aac (6')-le aph (2') & Single \\
\hline 168 & $\mathrm{~F}$ & CSF & CCU & TEC, VAN, CIP, E, TET, GEN & VanA, ermB, aac (6')-le aph (2') & C \\
\hline 169 & $\mathrm{~F}$ & Urine & $\mathrm{CCU}$ & TEC, VAN, CIP, E, TET, GEN & VanA, ermB, msrA, aac (6')-le aph (2') & C \\
\hline 184 & $\mathrm{~F}$ & Abscess & Internal & AMP, RIF, TEC, VAN, CIP, E, TET, GEN & VanA, ermB, aac (6')-le aph (2') & Single \\
\hline 185 & M & Urine & ICU & TEC, VAN, CIP, E, TET, GEN & VanA, ermB, msrA, aac (6')-le aph (2') & $A$ \\
\hline
\end{tabular}


Table 2 (continued)

\begin{tabular}{|c|c|c|c|c|c|c|}
\hline No. of isolates & $\begin{array}{l}\text { Male (M) } \\
\text { Female (F) }\end{array}$ & Source & Ward & Resistance patterns & Resistance genes & ERIC types \\
\hline 186 & M & Urine & Internal & AMP, TEC, VAN, CIP, E, TET, GEN & VanA, ermB, msrA, aac (6')-le aph (2') & $\mathrm{E}$ \\
\hline 187 & $\mathrm{~F}$ & Blood & ICU & TEC, VAN, CIP, E, TET & VanA, ermB, aac (6')-le aph (2') & $A$ \\
\hline 191 & $\mathrm{~F}$ & Urine & Internal & TEC, VAN, CIP, E, TET, GEN & VanA, ermB, aac (6')-le aph (2') & $A$ \\
\hline 196 & M & Urine & Surgery & RIF, TEC, VAN, CIP, E, TET & VanA, ermB, aac (6')-le aph (2') & $A$ \\
\hline 198 & $\mathrm{~F}$ & Urine & Internal & RIF, TEC, VAN, CIP, E, TET, GEN & VanA, ermB, aac (6')-le aph (2') & $A$ \\
\hline 220 & M & Urine & Emergency & AMP, RIF, TEC, VAN, CIP, E, TET, GEN, FM & VanA, ermB, aac (6')-le aph (2') & $A$ \\
\hline
\end{tabular}

[4]. Moreover, Transfer of the vanA gene cluster from Enterococcus species to other gram-positive pathogens such as Staphylococcus aureus is a very important phenomenon as increasing the public health concern [25]. Consistent with previous studies conducted in the Saudi Arabia and Ethiopia, in this study majority of the E. faecalis isolates (80\%) and all of vancomycin-resistant isolates had an MDR pattern and more than 55\% VRE isolates were resistant to $\geq 6$ tested antibiotics [26, 27].

In our results, $52.5 \%$ of $E$. faecalis isolates were Highlevel gentamicin resistance (HLGR) and gentamicin resistance is more prevalent among clinical vancomycinresistant E. faecalis isolates compared to vancomycinsusceptible E. faecalis. This finding is in accordance with previous studies in Iran and Kuwait [17, 28, 29] and was, in contrast, to report from Turkey [30]. The results of this study showed that $96.2 \%$ of vancomycin-resistant isolates and all HLGR isolates carried aac (6')-Ie aph (2") resistance gene. These results were in consistent with previous Iranian studies that showed high rate of HLGR enterococci contained the aac (6')-Ie aph ( $\left.2^{\prime \prime}\right)$ gene [7, 10, 15].

In the present study, more than $87 \%$ all of $E$. faecalis strains and $100 \%$ of vancomycin-resistant isolates were resistance to erythromycin. Decrease the effect of erythromycin on enterococci probably is due to the widespread use of macrolides family. In this study, similar to numerous studies indicated that $\operatorname{ermB}$ gene plays a predominant role in the development of $\mathrm{MLS}_{\mathrm{B}}$ phenotype among enterococci, the $\operatorname{ermB}$ gene was present in the all vancomycin-resistant isolates which were resistance to erythromycin $[15,17,31]$. But contrary to previous studies, in the present study, the investigated gene encoding efflux pump msrA was found in the $30.2 \%$ of VRE strains and $m e f A$ was not found in any of the isolates $[13,15]$.

Analysis of banding profiles of ERIC-PCR result showed most of the evaluated isolates have a close genetic relatedness. In this study, a total of 14 different ERIC profiles were observed among 53 VRE isolates. The strains that classified in the same ERIC types relatively presented similar drug resistance pattern. In our study, the majority of the isolates (27/53) were clustered in A type and most of isolates in these type were isolated from the same hospital ICU or internal ward and collected from urine and showed similar antibiotics resistance patterns. These data may suggest that an influence of epidemiological relatedness on the clustering of E. faecalis circulating strains in Isfahan city, as four clusters of VRE strains with high relatedness were recovered from the same period of isolation and location. This indicates the horizontal transfer of resistance genes among different types of E. faecalis isolates in hospital. Heterogeneity among isolates may contribute to facilitating survival of various enterococci strain in the environment of hospital. However, resistance to antimicrobial agents in such strains may lead to colonization and also enhancing potential spread from person to person in hospital setting.

In conclusion, the high incidence of antibiotic resistance in VRE isolates in our study can be viewed as one of the major public health crisis because the control of infections resulting from these resistant bacteria are difficult. This study demonstrated that high-level resistance to gentamicin, erythromycin and vancomycin in enterococci isolates were mainly related to the presence of aac (6')-Ie aph (2'), ermB and vanA genes, respectively. The ERIC-PCR analysis demonstrated that the evaluated 


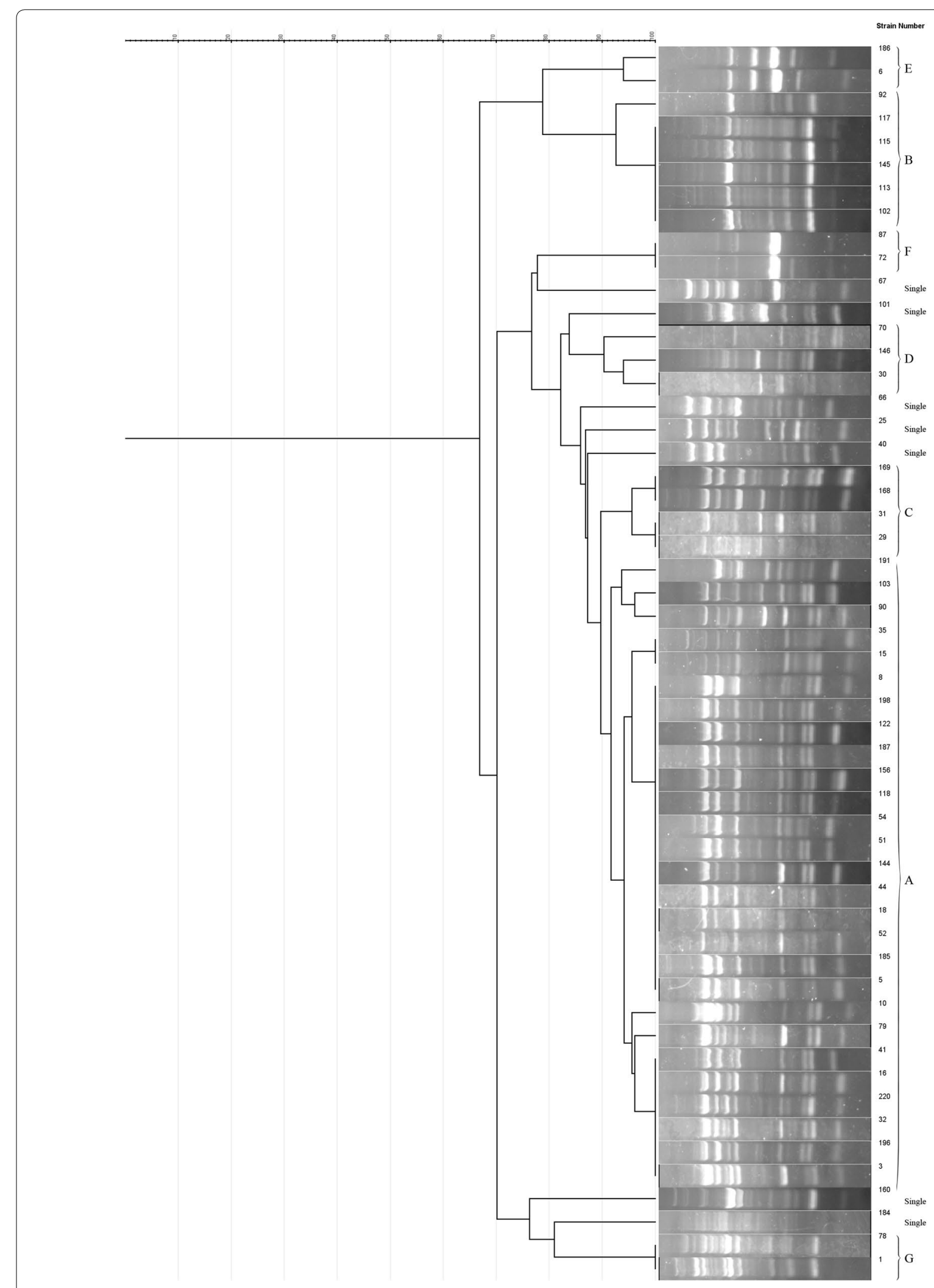

Fig. 1 Dendrogram showing relatedness between ERIC-PCR patterns of 53 vancomycin-resistant Enterococcus faecalis strains 
isolates were relatively heterogeneous and this may causes problems for the treatment of infections due to $E$. faecalis strains in hospitals.

\section{Limitation}

One limitation of this study is the apparently small number of enterococci isolates, especially VRE strains that were investigated for virulence and antibiotic resistance determinants. Second, to identification of the source for pathogen transmission and take preventive measures in hospital setting, molecular analysis of environmental specimens was required.

\section{Abbreviations}

AMEs: aminoglycoside-modifying enzymes; ERIC: enterobacterial repetitive intergenic consensus; erm: erythromycin resistant methylase; UTI: urinary tract infection; PCR: polymerase chain reaction; PFGE: pulsed-field electrophoresis; VRE: vancomycin-resistant enterococci; HLGR: high-level gentamicin resistance.

\section{Acknowledgements}

We are thankful to all members of Department of Microbiology, School of Medicine, at Isfahan University of Medical Sciences.

\section{Authors' contributions}

$\mathrm{SAH}, \mathrm{MH}, \mathrm{BNE}$ : designed and supervised, collected and analyzed the data and drafted the manuscript. All authors read and approved the final manuscript.

\section{Funding}

This was an original research paper from PhD thesis. This study was funded in part by a grant from the Isfahan University of Medical Sciences, [Grant no 396066]. The design of the study and collection, analysis, and interpretation of data and in writing the manuscript were supported by Isfahan University of Medical Sciences, Isfahan, Iran.

\section{Availability of data and materials}

The datasets used and/or analyzed during the current study are available from the corresponding author on reasonable request.

\section{Ethics approval and consent to participate}

The study protocol was approved by the Ethics Committee of Isfahan University of Medical Sciences (IR.MUI.REC.1396.3.066). In this study, bacteria isolated from clinical samples in the clinical microbiology laboratory were used.

\section{Consent for publication}

Not applicable.

\section{Competing interests}

The authors declare that they have no competing interests.

\section{Author details}

${ }^{1}$ Department of Microbiology, School of Medicine, Isfahan University of Medical Sciences, Hezar Jarib St, Isfahan, Iran. ${ }^{2}$ Infectious Diseases and Tropical Medicine Research Center, Isfahan University of Medical Sciences, Isfahan, Iran.

Received: 28 February 2019 Accepted: 22 May 2019

Published online: 27 May 2019

\section{References}

1. Heidari H, Hasanpour S, Ebrahim-Saraie HS, Motamedifar M. High incidence of virulence factors among clinical Enterococcus faecalis isolates in southwestern Iran. Infect Chemother. 2017:49:51-6.
2. Miller WR, Munita JM, Arias CA. Mechanisms of antibiotic resistance in enterococci. Expert Rev Anti Infect Ther. 2014;12:1221-36.

3. Miller WR, Murray BE, Rice LB, Arias CA. Vancomycin-resistant enterococci: therapeutic challenges in the 21st century. Infect Dis Clin N Am. 2016:30:415-39.

4. Kaveh M, Bazargani A, Ramzi M, Sedigh Ebrahim-Saraie H, Heidari H. Colonization rate and risk factors of vancomycin-resistant enterococci among patients received hematopoietic stem cell transplantation in Shiraz, southern Iran. Int J Organ Transplant Med. 2016;7:197-205.

5. Roghmann MC, Fink JC, Polish L, Maker T, Brewrink J, Morris JG Jr, Light PD. Colonization with vancomycin-resistant enterococci in chronic hemodialysis patients. Am J Kidney Dis. 1998;32:254-7.

6. Hemmati H, Khosravi M, Heidarzadeh A, Hashkavaei P, Refahibakhsh N. Vascular access and survival in hemodialysis patients in Rasht, Iran. Iran J Kidney Dis. 2011;5:34-7.

7. Taji A, Heidari H, Ebrahim-Saraie HS, Sarvari J, Motamedifar M. High prevalence of vancomycin and high-level gentamicin resistance in Enterococcus faecalis isolates. Acta Microbiol Immunol Hung. 2018;22:1-15.

8. Kafil HS, Asgharzadeh M. Vancomycin-resistant Enterococcus faecium and Enterococcus faecalis isolated from education hospital of Iran. Maedica. 2014;9:323-7.

9. Dadfarma N, Imani Fooladi AA, Oskoui M, Mahmoodzadeh Hosseini H. High level of gentamicin resistance (HLGR) among enterococcus strains isolated from clinical specimens. J Infect Public Health. 2013;6:202-8.

10. Behnood A, Farajnia S, Moaddab SR, Ahdi-Khosroshahi S, Katayounzadeh A. Prevalence of aac $\left(6^{\prime}\right)$-le-aph $\left(2^{\prime \prime}\right)$-la resistance gene and its linkage to Tn5281 in Enterococcus faecalis and Enterococcus faecium isolates from Tabriz hospitals. Iran J Microbiol. 2013;5:203-8.

11. Schmitz FJ, Sadurski R, Kray A, Boos M, Geisel R, Kohrer K, Verhoef J, Fluit AC. Prevalence of macrolide-resistance genes in Staphylococcus aureus and Enterococcus faecium isolates from 24 European university hospitals. J Antimicrob Chemother. 2000;45:891-4.

12. Leclercq R. Mechanisms of resistance to macrolides and lincosamides: nature of the resistance elements and their clinical implications. Clin Infect Dis. 2002:34:482-92.

13. Portillo A, Ruiz-Larrea F, Zarazaga M, Alonso A, Martinez JL, Torres C. Macrolide resistance genes in Enterococcus spp. Antimicrob Agents Chemother. 2000;44:967-71.

14. Singh A, Goering RV, Simjee S, Foley SL, Zervos MJ. Application of molecular techniques to the study of hospital infection. Clin Microbiol Rev. 2006;19:512-30.

15. Heidari $\mathrm{H}$, Emaneini $\mathrm{M}$, Dabiri $\mathrm{H}$, Jabalameli F. Virulence factors, antimicrobial resistance pattern and molecular analysis of Enterococcal strains isolated from burn patients. Microb Pathog. 2016;90:93-7.

16. CLSI. Performance standards for antimicrobial susceptibility testing; 26th Informational Supplement. CLSI document M100. Wayne: Clinical and Laboratory Standards Institute; 2016.

17. Emaneini M, Aligholi M, Aminshahi M. Characterization of glycopeptides, aminoglycosides and macrolide resistance among Enterococcus faecalis and Enterococcus faecium isolates from hospitals in Tehran. Pol J Microbiol. 2008:57:173-8.

18. Martin-Platero AM, Valdivia E, Maqueda M, Martinez-Bueno M. Characterization and safety evaluation of enterococci isolated from Spanish goats' milk cheeses. Int J Food Microbiol. 2009;132:24-32.

19. Heras J, Domínguez C, Mata E, Pascual V, Lozano C, Torres C, Zarazaga M. GelJ-a tool for analyzing DNA fingerprint gel images. BMC Bioinfor 2015;16:270. https://doi.org/10.1186/s12859-015-0703-0.

20. Emaneini M, Hosseinkhani F, Jabalameli F, Nasiri MJ, Dadashi M, Pouriran R, Beigverdi R. Prevalence of vancomycin-resistant Enterococcus in Iran: a systematic review and meta-analysis. Eur J Clin Microbiol Infect Dis. 2016;35:1387-92.

21. Armin S, Fallah F, Karimi A, Rashidan M, Shirdust M, Azimi L. Genotyping, antimicrobial resistance and virulence factor gene profiles of vancomycin resistance Enterococcus faecalis isolated from blood culture. Microb Pathog. 2017;109:300-4.

22. Bahram F, Farhad BH, Mohammad E, Marzieh A, Farrokh AN, Bahram K. Detection of vancomycin resistant enterococci (VRE) isolated from urinary tract infections (UTI) in Tehran, Iran. DARU J Pharm Sci. 2006;14:141-5. 
23. Sabouni F, Movahedi Z, Mahmoudi S, Pourakbari B, Keshavarz Valian S, Mamishi S. High frequency of vancomycin resistant Enterococcus faecalis in children: an alarming concern. J Prev Med Hyg. 2016;57:E201-e204.

24. Rengaraj R, Mariappan S, Sekar U, Kamalanadhan A. Detection of vancomycin resistance among Enterococcus faecalis and Staphylococcus aureus. J Clin Diagn Res. 2016;10:Dc04-6.

25. McGuinness WA, Malachowa N, DeLeo FR. Vancomycin resistance in Staphylococcus aureus. Yale J Biol Med. 2017;90:269-81.

26. Toru M, Beyene G, Kassa T, Gizachew Z, Howe R, Yeshitila B. Prevalence and phenotypic characterization of Enterococcus species isolated from clinical samples of pediatric patients in Jimma University Specialized Hospital, south west Ethiopia. BMC Res Notes. 2018;11:281.

27. Farman M, Yasir M, Al-Hindi RR, Farraj SA, Jiman-Fatani AA, Alawi M, Azhar El. Genomic analysis of multidrug-resistant clinical Enterococcus faecalis isolates for antimicrobial resistance genes and virulence factors from the western region of Saudi Arabia. Antimicrob Resist Infect Control. 2019;8:55.

28. Feizabadi MM, Maleknejad P, Asgharzadeh A, Asadi S, Shokrzadeh L, Sayadi S. Prevalence of aminoglycoside-modifying enzymes genes among isolates of Enterococcus faecalis and Enterococcus faecium in Iran. Microb Drug Resist. 2006;12:265-8.

29. Udo EE, Al-Sweih N, John P, Jacob LE, Mohanakrishnan S. Characterization of high-level aminoglycoside-resistant enterococci in Kuwait hospitals. Microb Drug Resist. 2004;10:139-45.

30. Kacmaz B, Aksoy A. Antimicrobial resistance of enterococci in Turkey. Int J Antimicrob Agents. 2005:25:535-8.

31. Hidano A, Yamamoto T, Hayama Y, Muroga N, Kobayashi S, Nishida T, Tsutsui T. Unraveling antimicrobial resistance genes and phenotype patterns among Enterococcus faecalis isolated from retail chicken products in Japan. PLoS ONE. 2015;10:e0121189.

\section{Publisher's Note}

Springer Nature remains neutral with regard to jurisdictional claims in published maps and institutional affiliations.
Ready to submit your research? Choose BMC and benefit from:

- fast, convenient online submission

- thorough peer review by experienced researchers in your field

- rapid publication on acceptance

- support for research data, including large and complex data types

- gold Open Access which fosters wider collaboration and increased citations

- maximum visibility for your research: over $100 \mathrm{M}$ website views per year

At $\mathrm{BMC}$, research is always in progress.

Learn more biomedcentral.com/submissions 